\title{
TWO-PHASE FLOW PHENOMENA IN A HORIZONTAL PIPE WITH A SUDDEN CONTRACTION: EFFECTS OF CONTRACTION RATIO ON FILM BEHAVIOUR
}

\author{
TAKAHIRO FUJIMATSU, MIZUKI KITO \& KUNIKAZU KONDO \\ Department of Mechanical Engineering, National Institute of Technology, Suzuka College, Japan
}

\begin{abstract}
Experimental studies were conducted on the behaviour of water films in a horizontal pipe with a sudden contraction to achieve a fundamental understanding of the film mechanisms of annular flow using highspeed video imaging analysis. The sudden contraction area ratios $A_{C}=\left(d_{2} / d_{1}\right)^{2}=0.36$ and 0.64 , where $\mathrm{d}_{1}$ is the inlet pipe diameter $(50 \mathrm{~mm})$ and $\mathrm{d}_{2}$ is the contracted pipe diameter were examined. The experiments were carried out for various values of superficial gas and liquid velocities. The superficial gas velocity after mixing $\left(\mathrm{j}_{\mathrm{G} 1}\right)$ ranged from 18.02 to $24.41 \mathrm{~m} / \mathrm{s}$ (the calculated velocity from the crosssectional at the sudden contraction was $\mathrm{j}_{\mathrm{G} 2}=27.98-67.39 \mathrm{~m} / \mathrm{s}$ ) and the superficial liquid velocity ( $\mathrm{j}_{\mathrm{L} 1}$ ) ranged from $8.62 \times 10^{-2}$ to $1.23 \times 10^{-1} \mathrm{~m} / \mathrm{s}\left(\mathrm{j}_{\mathrm{L} 2}=1.35 \times 10^{-1}-3.42 \times 10^{-1} \mathrm{~m} / \mathrm{s}\right)$. Four flow regimes were observed after the sudden contraction, namely, huge-wave (HW), two-dimensional disturbance wave $\left(\mathrm{DW}_{1}\right)$ which is formed perpendicularly to a pipe axis having a distinct coherence, three-dimensional disturbance wave $\left(\mathrm{DW}_{2}\right)$ which is formed obliquely to the pipe axis, and bow wave $\left(\mathrm{DW}_{3}\right)$ which is transitional wave to "Misty wave" from $\mathrm{DW}_{2}$. The disturbance wave occurrence frequencies were studied under various conditions of flow rate combination of air and water. $\mathrm{DW}_{2}$ occurs over wide range of the superficial gas and liquid velocities. As the superficial gas velocity and the superficial liquid velocity increase, two-dimensional disturbance waves change into three-dimensional ones. The wave occurrence frequencies in the pipe with the sudden contraction ratio $\mathrm{A}_{\mathrm{C}}=0.36$ were mostly higher than those in the pipe with $A_{C}=0.64$.
\end{abstract}

Keywords: sudden contraction, disturbance wave, flow regime, wave occurrence frequency.

\section{INTRODUCTION}

Gas-liquid two-phase flows through orifices which are used for controlling pressure or flow rate, are important in multiphase flow measurements [1]. For instance, they are commonly found in pipelines in nuclear power, petroleum, geothermal and food processing industries. In order to predict cavitation erosion rate or improve the measurement accuracy and efficiency, many studies regarding the measurements of two-phase flows have been conducted numerically and experimentally [2]-[5]. A fundamental understanding of the gasliquid two-phase flow is also essential for designing optimal energy-related apparatus in thermal energy plants, nuclear power plants, chemical plants as well as cooling and heating equipment. Flow pattern changes mainly depend on a number of parameters, such as flow direction, fluid property, flow conditions and channel configurations. Because it is, therefore, necessary to take the flow pattern and regime into account for predicting two-phase pressure drops in different pipe configurations and suitable operating conditions, a number of investigations have been made with regard to the classification of flow patterns in different channel configurations. Chang et al. [6] investigated air-water flows through horizontal and vertical U-bend rectangular channels. They analyzed the two-phase flow patterns by visualizing the interfacial flow transitions through the U-bend in order to understand the pressure drop and the heat transfer process. In addition, the effects of channel height-to-width ratio on the behaviour of air-water flows were demonstrated. They presented that the slugannular flow in flow pattern maps shifted towards the higher superficial gas velocities as the height-to-width ratio decreased. Air-water flows through horizontal to vertical through a 
90-degree bend were analyzed by Saidj et al. [7]. They identified the flow patterns both in the horizontal pipe and the vertical pipe upstream, using the Probability Density Function (PDF) of the time series of the cross sectional averaged void fraction. Hsu et al. [8] examined two-phase flow patterns in 90-degree bends with small diameter tubes. They studied flow patterns in 90-degree bends installed upward horizontally, and downward. They observed a liquid flow reversal and a swirled motion for the upward flow arrangement. Whalley [9] studied air-water flows in a helically coiled tube. They showed the differences in the liquid film thickness and liquid film flow rate around the tube periphery between presented flows and vertical annular flows. Azzopardi and Whalley [10] investigated the effects of flow patterns in a $\mathrm{T}$ junction. They found that the entering flow direction of air-water flows was strongly dependent on the flow patterns upstream the junction. Saisorn and Wongwises [11] compared air-water flows through a horizontal circular micro-channel with two-phase flow through ordinarily size channels. They classified the observed flow patterns into three flow regimes and showed comparisons of the observed flow patterns with the flow regime maps proposed by some previous researchers. Few reports, however, have focused on the film mechanism of an annular mist flow in a horizontal pipe with a sudden contraction. Schmidt and Friedel [12] conducted extensive pressure drop measurements across a sudden contraction and provided a new pressure drop model. Chen et al. [13] studied the pressure drops and flow pattern changes across sudden contractions in small rectangular channels having different area ratios. However, a clear understanding of flow patterns is still expected and it is necessary to predict flow-pattern transitions in a horizontal pipe with a sudden contraction due to their physical and practical significance, as well as their feature complexity.

The authors have reported the flow regime transitions in a horizontal pipe with a sudden contraction and measured the water-drop size in the annular mist flow using immersion liquid method [14], [15]. In this paper, the effects of the contraction area ratio on film behaviour were investigated by flow observations and measurements of disturbance wave occurrence frequency in order to contribute the fundamental data concerning to film characteristics in air-water horizontal annular two-phase flow with a sudden contraction.

\section{EXPERIMENTAL SET UP}

A schematic diagram of the experimental apparatus is shown in Fig. 1. Compressed air was supplied from a compressor to the mixing device where it combines with water from a storage tank. The mixing device consisted of an annular section surrounding a porous sinter wall. The test section was made of transparent acrylic resin in order to allow flow behaviour observations and consisted of an inner diameter pipe $d_{1}=50 \mathrm{~mm}, 4320 \mathrm{~mm}$ long upstream and $\mathrm{d}_{2}=30 \mathrm{~mm}$ or $40 \mathrm{~mm}$ downstream the horizontal system. The contraction area ratios $A_{C}=\left(d_{2} / d_{1}\right)^{2}$ were obtained to be 0.36 and 0.64 .

The experiments were carried out for various values of superficial gas and liquid velocities. The superficial gas velocity after mixing $\left(\mathrm{j}_{\mathrm{G} 1}\right)$ ranged from 18.02 to $24.41 \mathrm{~m} / \mathrm{s}$ (the calculated velocity from the cross-sectional at the sudden contraction was $\mathrm{j}_{\mathrm{G} 2}=27.98$ $67.39 \mathrm{~m} / \mathrm{s}$ ) and the superficial liquid velocity $\left(\mathrm{j}_{\mathrm{L} 1}\right)$ ranged from $8.62 \times 10^{-2}$ to $1.23 \times 10^{-1} \mathrm{~m} / \mathrm{s}$ $\left(\mathrm{j}_{\mathrm{L} 2}=1.35 \times 10^{-1}-3.42 \times 10^{-1} \mathrm{~m} / \mathrm{s}\right)$ as summarised in Tables 1 and 2 . The superficial gas and liquid velocities were calculated from mass flow rates $\left(G_{A}\right.$ and $\left.G_{L}\right)$, which were obtained from the changes $\left(h_{A}\right.$ and $\left.h_{L}\right)$ in pressure head upstream through a quadrant edged nozzle with the flow coefficients $(\alpha)$. The inlet temperature was measured using thermocouples to obtain the density and viscosity, from which the Reynolds numbers $\left(\operatorname{Re}_{\mathrm{G} 1}\right.$ and $\left.\mathrm{Re}_{\mathrm{L} 1}\right)$ were calculated as shown in Tables 1 and 2. A detailed flow observation using a high-speed video 


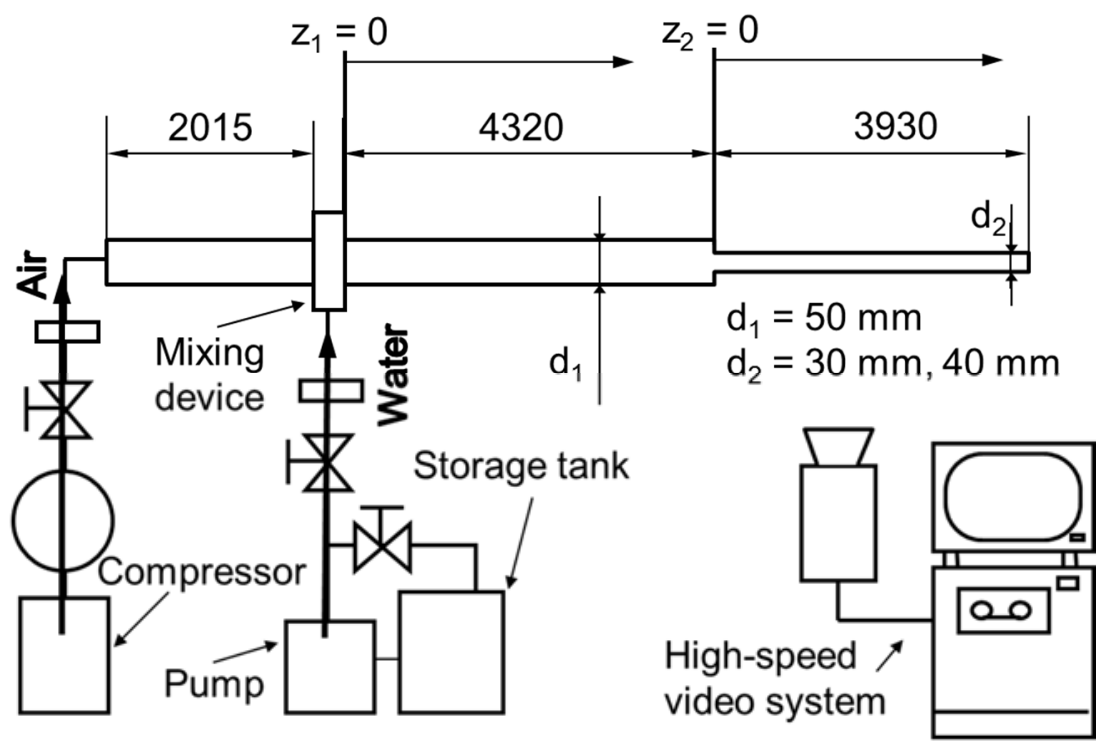

Figure 1: Experimental apparatus.

Table 1: Summary of the experimental conditions of gas phase.

\begin{tabular}{ccccccc}
\hline $\mathrm{h}_{\mathrm{A}} \mathrm{mmAq}$ & $\mathrm{G}_{\mathrm{A}} \mathrm{kg} / \mathrm{s}$ & $\alpha$ & $\mathrm{j}_{\mathrm{G} 1} \mathrm{~m} / \mathrm{s}$ & \multicolumn{2}{c}{$\mathrm{j}_{\mathrm{G} 2} \mathrm{~m} / \mathrm{s}$} & $\mathrm{Re}_{\mathrm{G} 1}$ \\
\cline { 5 - 6 } & & & & $\mathrm{A}_{\mathrm{C}}=0.36$ & $\mathrm{~A}_{\mathrm{C}}=0.64$ & \\
\hline 250 & $4.23 \times 10^{-2}$ & 0.779 & 18.02 & 27.98 & 49.75 & 59237 \\
350 & $5.02 \times 10^{-2}$ & 0.783 & 21.45 & 33.30 & 59.21 & 70328 \\
450 & $5.72 \times 10^{-2}$ & 0.786 & 24.41 & 37.90 & 67.39 & 80085 \\
\hline
\end{tabular}

Table 2: Summary of the experimental conditions of liquid phase.

\begin{tabular}{cccccc}
\hline $\mathrm{h}_{\mathrm{L}} \mathrm{mmAq}$ & $\mathrm{G}_{\mathrm{L}} \mathrm{kg} / \mathrm{s}$ & $\mathrm{j}_{\mathrm{L} 1} \mathrm{~m} / \mathrm{s}$ & \multicolumn{2}{c}{$\mathrm{j}_{\mathrm{L} 2} \mathrm{~m} / \mathrm{s}$} & $\mathrm{Re}_{\mathrm{L} 1}$ \\
\cline { 4 - 5 } & & & $\mathrm{A}_{\mathrm{C}}=0.36$ & $\mathrm{~A}_{\mathrm{C}}=0.64$ & \\
\hline 50 & $1.67 \times 10^{-1}$ & $8.62 \times 10^{-2}$ & $1.35 \times 10^{-1}$ & $2.39 \times 10^{-1}$ & 4485 \\
55 & $1.76 \times 10^{-1}$ & $9.00 \times 10^{-2}$ & $1.41 \times 10^{-1}$ & $2.50 \times 10^{-1}$ & 4683 \\
60 & $1.84 \times 10^{-1}$ & $9.47 \times 10^{-2}$ & $1.48 \times 10^{-1}$ & $2.63 \times 10^{-1}$ & 4963 \\
65 & $1.91 \times 10^{-1}$ & $9.80 \times 10^{-2}$ & $1.53 \times 10^{-1}$ & $2.72 \times 10^{-1}$ & 5136 \\
70 & $1.99 \times 10^{-1}$ & $1.03 \times 10^{-1}$ & $1.60 \times 10^{-1}$ & $2.85 \times 10^{-1}$ & 5412 \\
75 & $2.06 \times 10^{-1}$ & $1.06 \times 10^{-1}$ & $1.65 \times 10^{-1}$ & $2.93 \times 10^{-1}$ & 5544 \\
80 & $2.13 \times 10^{-1}$ & $1.10 \times 10^{-1}$ & $1.72 \times 10^{-1}$ & $3.05 \times 10^{-1}$ & 5840 \\
85 & $2.19 \times 10^{-1}$ & $1.13 \times 10^{-1}$ & $1.76 \times 10^{-1}$ & $3.13 \times 10^{-1}$ & 5984 \\
90 & $2.23 \times 10^{-1}$ & $1.17 \times 10^{-1}$ & $1.82 \times 10^{-1}$ & $3.24 \times 10^{-1}$ & 6169 \\
95 & $2.32 \times 10^{-1}$ & $1.19 \times 10^{-1}$ & $1.86 \times 10^{-1}$ & $3.31 \times 10^{-1}$ & 6302 \\
100 & $2.38 \times 10^{-1}$ & $1.23 \times 10^{-1}$ & $1.92 \times 10^{-1}$ & $3.42 \times 10^{-1}$ & 6550 \\
\hline
\end{tabular}


camera revealed the flow regime transitions at $\mathrm{z}_{2} / \mathrm{d}_{2}=10,40$ and 80 denoting the normalised streamwise distance from the sudden contraction. Passing frequencies of disturbance waves were measured for ten minutes by visual observations at every measurement point under each condition. The average values of the measured frequencies which were taken for three minutes; one minute at the beginning, at the middle and at the end of the measurements, were used as disturbance wave occurrence frequencies, which will be explained in Section 3.2.

\section{RESULTS AND DISCUSSIONS}

\subsection{Flow regime}

The flow regime transitions were examined to elucidate the developing process of the twophase flow. In a horizontal pipe a number of different flow patterns may be observed depending on the conditions of the flow rate combination of air and water [16]. Fig. 2(a) shows "Stratified flow" in which the two phases flow separately with a relatively smooth interface at low gas and liquid velocities. Fig. 2(b) shows "Wavy flow" in which the interface becomes disturbed by waves traveling in the direction of flow. At high gas flow rates the liquid flows in an annular film on the pipe wall with the gas moving rapidly in a central core. At low liquid flow rates the film is relatively smooth with small ripples as shown in Fig. 2(c). The liquid became entrained into the gas in droplet form, resulting Fig. 2(d). As the liquid rate is increased the surface of the film becomes distorted with the formation of "Huge waves" and "Disturbance waves".

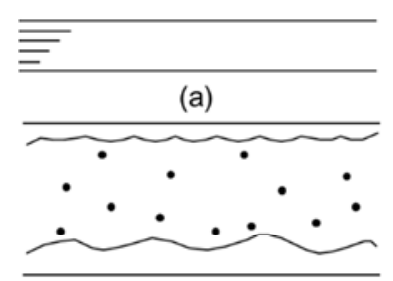

(d)

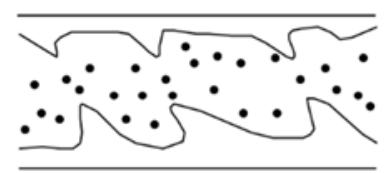

(g)

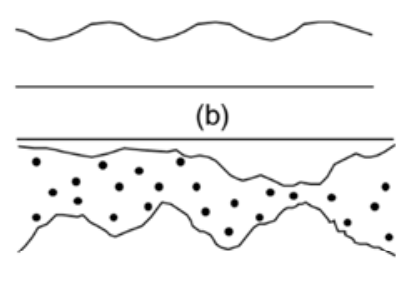

(e)

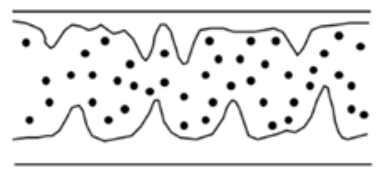

(h)

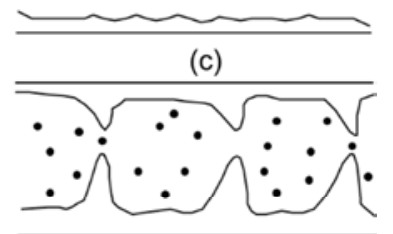

(f)

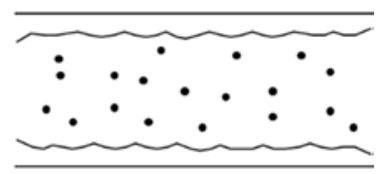

(i)

Figure 2: Flow regime in horizontal flow. (a) Stratified flow; (b) Wavy flow; (c) Ripple; (d) Quasi-ripple; (e) Huge wave (HW); (f) Two-dimensional disturbance wave $\left(\mathrm{DW}_{1}\right)$; (g) Three-dimensional disturbance wave $\left(\mathrm{DW}_{2}\right)$; (h) Quasi-bow wave $\left(\mathrm{DW}_{3}\right)$; and (i) Misty wave.

An annular mist flow, in which a liquid flows on the wall of a pipe as a film and a gas flows in the centre [17], was observed after the sudden contraction in the present experimental range, while "Wavy flow" was observed before the sudden contraction. The visual observation allowed a more detailed classification of the annular mist flows. Some 
photos of observed typical flow regimes are shown in Fig. 3. Four flow regimes were observed; huge-wave $(\mathrm{HW})$, two-dimensional disturbance wave $\left(\mathrm{DW}_{1}\right)$, three-dimensional disturbance wave $\left(\mathrm{DW}_{2}\right)$ and quasi-bow wave $\left(\mathrm{DW}_{3}\right)$ which was a transitional wave to "Misty wave" from $\mathrm{DW}_{2}$. $\mathrm{DW}_{1}$ is formed perpendicularly to the pipe axis and coherent [18] around the pipe circumference, while $\mathrm{DW}_{2}$ is distorted in the streamwise direction, then a part of the ringwise waves begins to be broken. These waves with no coherence around the pipe circumference three-dimensional disturbance waves were termed $\mathrm{DW}_{2}$, as distinguished from $\mathrm{DW}_{1}$. At high gas and liquid velocities, $\mathrm{DW}_{3}$ which was transitional wave to "Misty wave" from $\mathrm{DW}_{2}$ was observed. $\mathrm{DW}_{3}$ is a comparable wave to "Bow wave" which has been observed in the literature [18] for two-phase flow through a large diameter vertical pipe.

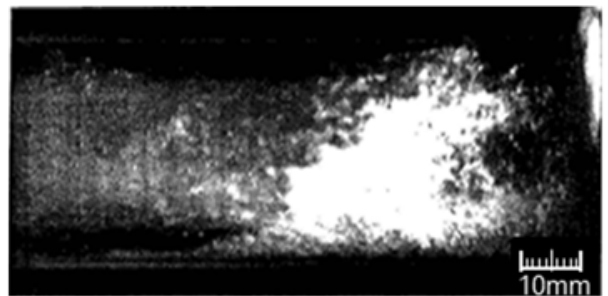

(a)

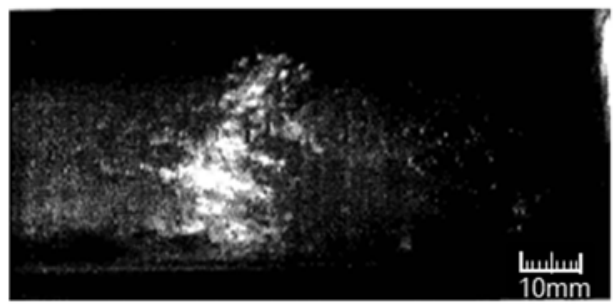

(c)

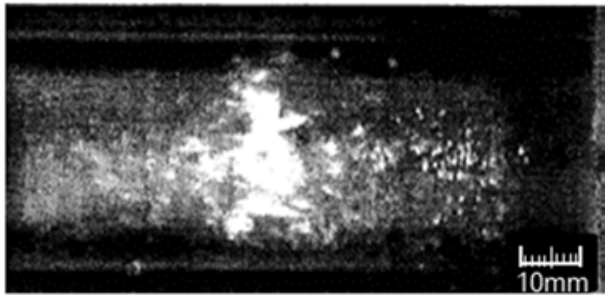

(b)

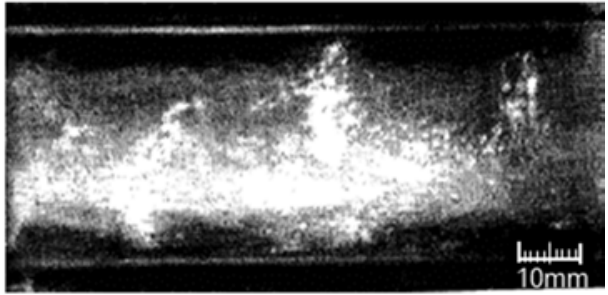

(d)

Figure 3: Photos of typical flow regime. (a) $\mathrm{HW}$; (b) $\mathrm{DW}_{1}$; (c) $\mathrm{DW}_{2}$; and (d) $\mathrm{DW}_{3}$.

Figs 4 and 5 show the observed flow regime maps at $\mathrm{z}_{2} / \mathrm{d}_{2}=10,40,80$ downstream the sudden contraction for the air-water flows in a horizontal pipe with a sudden contraction of $A_{C}=0.36$ and 0.64 , respectively. The flow pattern transition curves suggested by Mandhane et al. [19] and Taitel et al. [20] are illustrated by broken lines in Figs 4 and 5. The observed flows under the experimental conditions were categorized as annular regimes by them and classified more in detail into four flow regimes, as mentioned above. The flow regime $\mathrm{DW}_{1}+\mathrm{DW}_{2}$ is observed and subsequently $\mathrm{DW}_{1}+\mathrm{DW}_{2}+\mathrm{DW}_{3}, \mathrm{DW}_{2}+\mathrm{DW}_{3}$ as the superficial gas and liquid velocities increase in Fig. 4. Moreover, as the normalized axial distance $\mathrm{z}_{2} / \mathrm{d}_{2}$ increases up to 80 , the flow regime shifts from $\mathrm{DW}_{1}+\mathrm{DW}_{2}$ to $\mathrm{DW}_{1}+\mathrm{DW}_{2}+\mathrm{DW}_{3}$ at the same $\mathrm{j}_{\mathrm{G} 1}$ and $\mathrm{j}_{\mathrm{L} 1}$. $\mathrm{DW}_{1}$ region narrows and alternately $\mathrm{DW}_{3}$ region widens toward downstream after the sudden contraction. In Fig. 5(a) and (b), as the superficial gas and liquid velocities increase, the flow regime $\mathrm{DW}_{1}+\mathrm{DW}_{2}$ is observed and subsequently $\mathrm{DW}_{1}+\mathrm{DW}_{2}+\mathrm{DW}_{3}$, which is the similar evolution occurred in Fig. 4, expect that no flow regime of $\mathrm{DW}_{2}+\mathrm{DW}_{3}$ is observed in Fig. 5. Fig. 5(c), in contrast, indicates the existence of HW. The flow regime $\mathrm{HW}+\mathrm{DW} \mathrm{W}_{1}+\mathrm{DW}_{2}$ is observed at low $\mathrm{j}_{\mathrm{G} 1}$ and high $\mathrm{j}_{\mathrm{L} 1}, \mathrm{z}_{2} / \mathrm{d}_{2}=80$ in Fig. 5(c). HW occurrence at lower $\mathrm{j}_{\mathrm{G} 1}$ is observed at lower $\mathrm{j}_{\mathrm{L} 1}$. When $\mathrm{DW}_{3}$ occurs, HW disappears. 
58 Computational and Experimental Methods in Multiphase and Complex Flow X

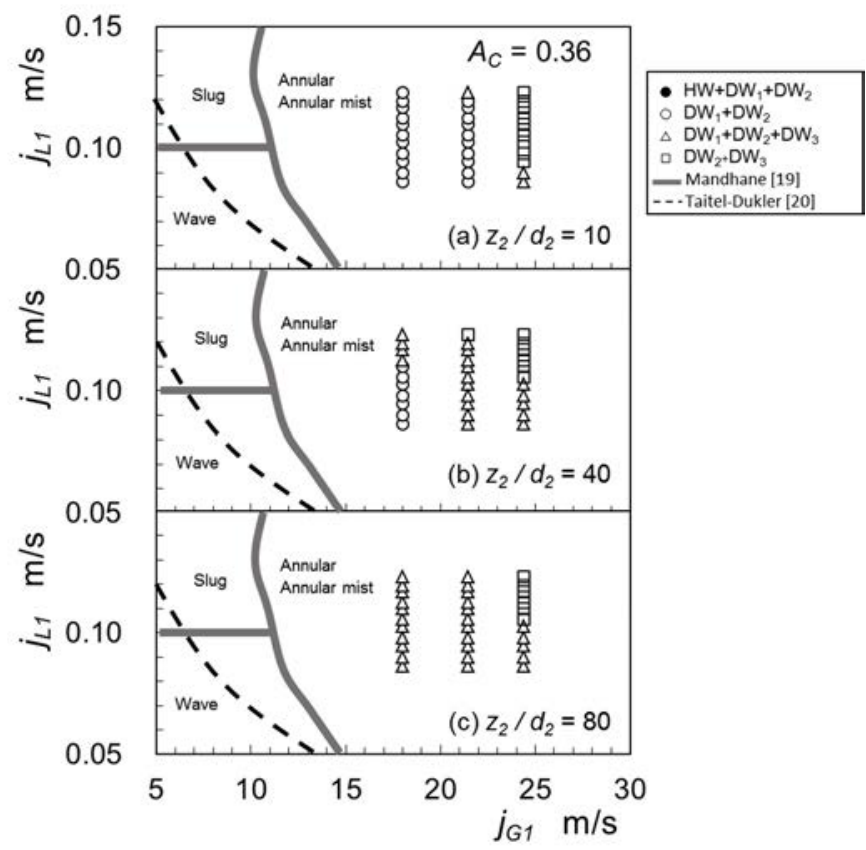

Figure 4: Flow regime map for $\mathrm{A}_{\mathrm{C}}=0.36$.

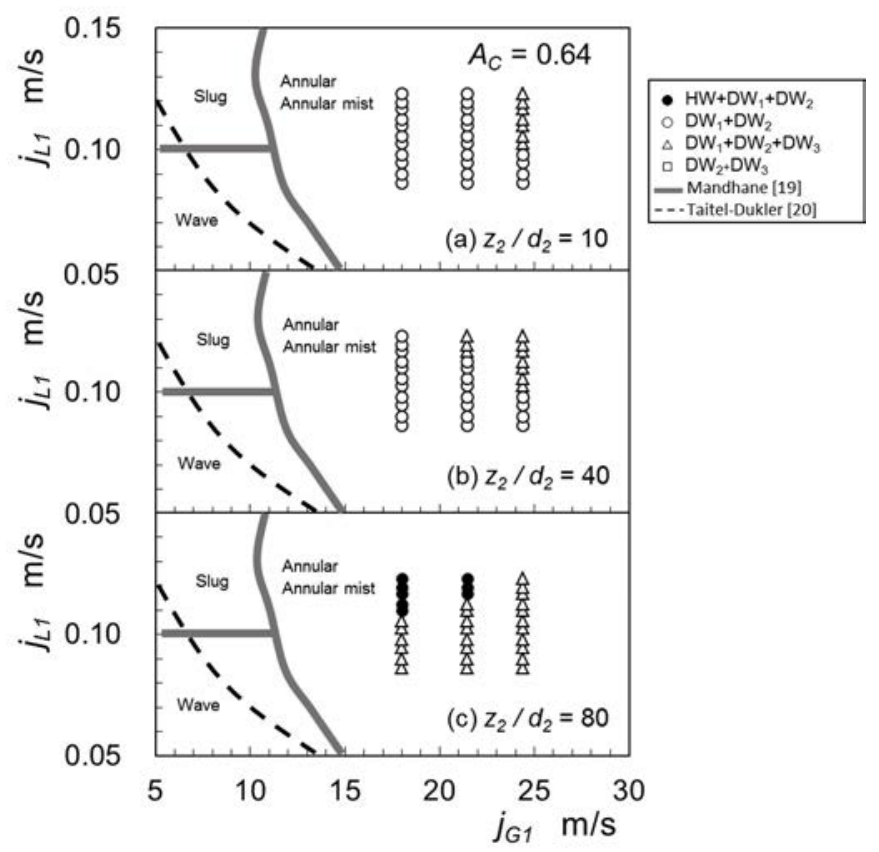

Figure 5: Flow regime map for $\mathrm{A}_{\mathrm{C}}=0.64$. 
3.2 Effect of the superficial gas velocity on mean frequencies for disturbance wave

Fig. 6(a) and (b) show the change in the mean frequency of disturbance wave occurrence with the superficial gas velocity $\mathrm{j}_{\mathrm{G} 1}$ at $\mathrm{j}_{\mathrm{L} 1}=1.10 \times 10^{-1} \mathrm{~m} / \mathrm{s}, \mathrm{z}_{2} / \mathrm{d}_{2}=20$ and 80 , respectively. The authors define the wave occurrence frequency as the mean number of waves per second passing an arbitrary point in the pipe. The frequencies of $\mathrm{DW}_{1}, \mathrm{DW}_{2}, \mathrm{DW}_{3}$ and $\mathrm{DW}$ : the sum of these frequencies, are denoted by $f_{\mathrm{D} 1}, f_{\mathrm{D} 2}, \mathrm{f}_{\mathrm{D} 3}$ and $\mathrm{f}_{\mathrm{D}}$, respectively.

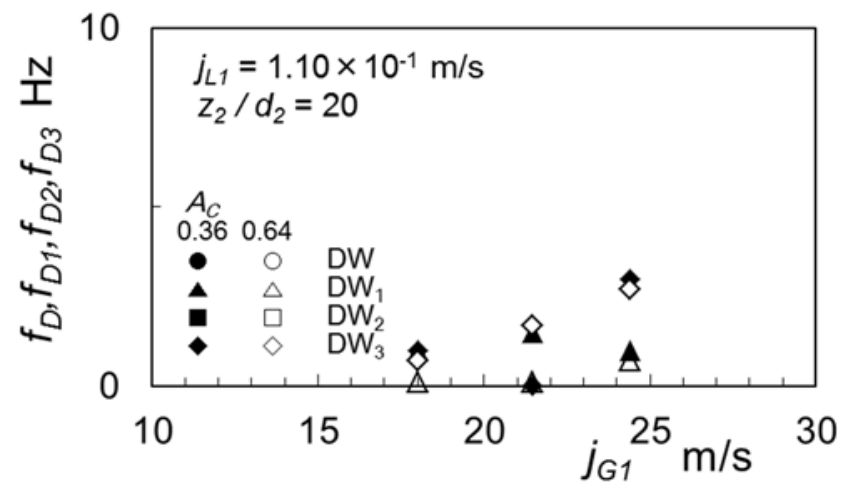

(a)

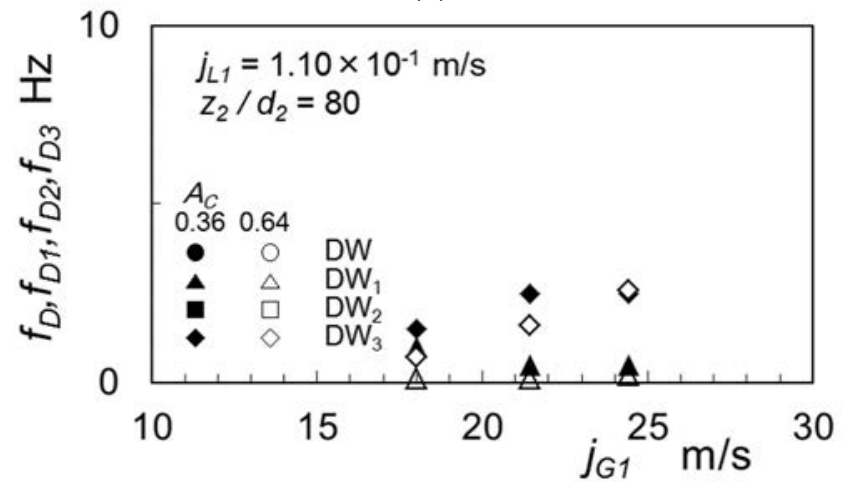

(b)

Figure 6: Effect of the superficial gas velocity on mean frequencies for disturbance waves $\left(\mathrm{j}_{\mathrm{L} 1}=1.10 \times 10^{-1} \mathrm{~m} / \mathrm{s}\right)$. (a) $\mathrm{z}_{2} / \mathrm{d}_{2}=20$; and (b) $\mathrm{z}_{2} / \mathrm{d}_{2}=80$.

The mean frequency values obtained in flows through the sudden contraction of $\mathrm{A}_{\mathrm{C}}=0.36$ are higher than those in the case of $\mathrm{A}_{\mathrm{C}}=0.64 . \mathrm{DW}_{2}$ occurs over wide range of the superficial gas and liquid velocities in the both cases of $\mathrm{A}_{\mathrm{C}}=0.36$ and $0.64 . \mathrm{DW}_{2}, \mathrm{DW}_{3}$ and $\mathrm{DW}$ increase with the superficial gas velocity. $\mathrm{DW}_{1}$, in contrast, decreases with $\mathrm{j}_{\mathrm{G} 1}$. $\mathrm{DW}_{3}$ is observed at high velocity $\mathrm{j}_{\mathrm{G} 1}$. At $\mathrm{z}_{2} / \mathrm{d}_{2}=80$ as shown in Fig. $6(\mathrm{~b})$, the frequencies of $\mathrm{DW}_{2}$ and $\mathrm{DW}$ for $\mathrm{A}_{\mathrm{C}}$ $=0.36$ are nearly constant up to the superficial gas velocity $21.45 \mathrm{~m} / \mathrm{s}$ and decrease at $\mathrm{j}_{\mathrm{G} 1}=$ $24.45 \mathrm{~m} / \mathrm{s}$, while the frequency of $\mathrm{DW}_{3}$ slightly increases. Thus, $\mathrm{DW}_{2}$ decreases after the appearance of $\mathrm{DW}_{3}$. On the other hand, the frequency of $\mathrm{DW}_{2}$ and $\mathrm{DW}$ for $\mathrm{A}_{\mathrm{C}}=0.64$ gradually increase. The increasing rate of DW at $\mathrm{z}_{2} / \mathrm{d}_{2}=80$ is smaller than that at $\mathrm{z}_{2} / \mathrm{d}_{2}=20$. The increasing rate of DW caused by the increasing $\mathrm{j}_{\mathrm{G} 1}$ is moderated with increasing $\mathrm{z}_{2} / \mathrm{d}_{2}$. 
3.3 Effect of the superficial liquid velocity on mean frequencies for disturbance waves

Fig. 7(a) and (b) show the change in the mean frequency of disturbance wave with the superficial liquid velocity $\mathrm{j}_{\mathrm{L} 1}$ at $\mathrm{j}_{\mathrm{G} 1}=21.45 \mathrm{~m} / \mathrm{s}, \mathrm{z}_{2} / \mathrm{d}_{2}=20$ and 80 , respectively.

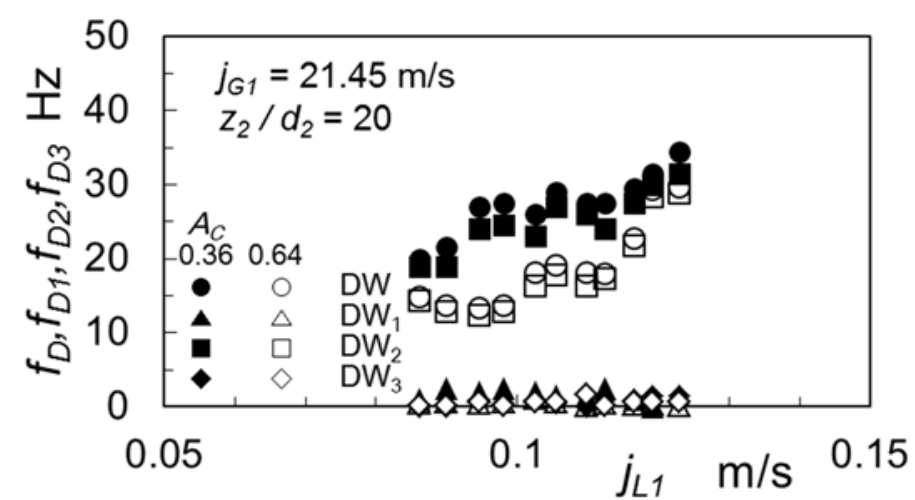

(a)

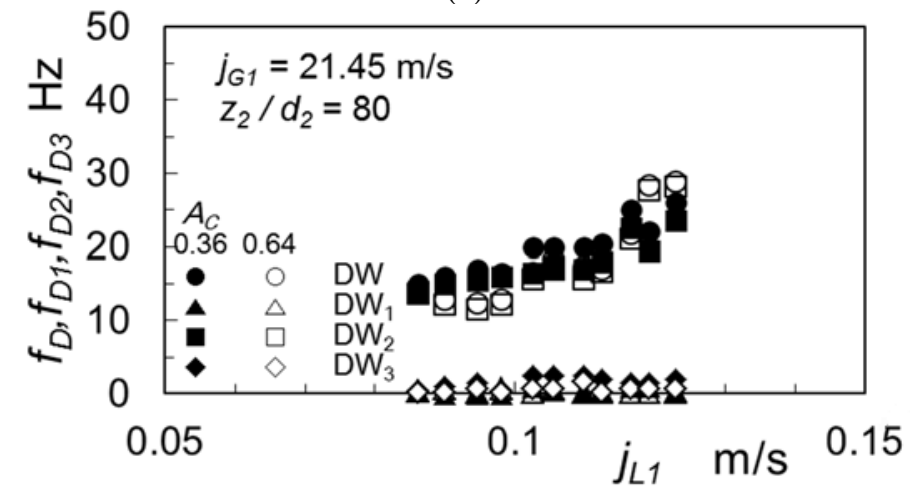

(b)

Figure 7: Effect of the superficial liquid velocity on mean frequencies for disturbance waves $\left(\mathrm{j}_{\mathrm{G} 1}=21.45 \mathrm{~m} / \mathrm{s}\right)$. (a) $\mathrm{z}_{2} / \mathrm{d}_{2}=20$; and (b) $\mathrm{z}_{2} / \mathrm{d}_{2}=80$.

The frequencies of $\mathrm{DW}_{2}$ and $\mathrm{DW}$ for $\mathrm{A}_{\mathrm{C}}=0.36$ increase constantly. $\mathrm{DW}_{1}$ occurs more frequent than $\mathrm{DW}_{3}$ does, although their occurrence frequencies are much smaller than that of $\mathrm{DW}_{2}$. On the other hand, the frequencies of $\mathrm{DW}_{2}$ and $\mathrm{DW}$ for $\mathrm{A}_{\mathrm{C}}=0.64$ are nearly constant up to $\mathrm{j}_{\mathrm{L} 1}=1.13 \times 10^{-1} \mathrm{~m} / \mathrm{s}$ and increase rapidly as the superficial liquid velocity increases. $\mathrm{DW}_{1}$ and $\mathrm{DW}_{3}$ occur over wide range of the superficial liquid velocity, although the occurrence frequencies of them are much smaller than that of $\mathrm{DW}_{2}$. Fig. 7(a) clearly indicates effects of the contraction area ratio at low superficial liquid velocity.

Fig. 7(b) indicates that little influence of the sudden contraction area ratios on the mean frequencies of disturbance waves are observed. The frequencies of $\mathrm{DW}_{2}$ in the both cases of $\mathrm{A}_{\mathrm{C}}=0.36$ and 0.64 increase with the superficial liquid velocity. It follows that the frequency of DW increases constantly. $\mathrm{DW}_{3}$ for $\mathrm{A}_{\mathrm{C}}=0.36$ is observed over wide range of the superficial liquid velocity at $\mathrm{z}_{2} / \mathrm{d}_{2}=80$, while $\mathrm{DW}$ occurs at $\mathrm{z}_{2} / \mathrm{d}_{2}=20$. The mean frequency distributions become similar as $\mathrm{z}_{2} / \mathrm{d}_{2}$ increases. 


\subsection{Mean frequencies for disturbance waves in the normalized axial direction}

Fig. 8 shows the mean frequencies for disturbance waves in the normalized axial direction. DW for $\mathrm{A}_{\mathrm{C}}=0.36$ continually decreases, while that for $\mathrm{A}_{\mathrm{C}}=0.64$ decreases up to $\mathrm{z}_{2} / \mathrm{d}_{2}=20$ and then stays quasi constant. $\mathrm{DW}_{2}$, which mainly occurs in the normalized axial direction, decreases in a similar way as DW. $\mathrm{DW}_{1}$ is much less than $\mathrm{DW}_{2}$ and disappears at the downstream. $\mathrm{DW}_{3}$ gradually increases in the downstream. The change tendency of disturbance waves with $\mathrm{j}_{\mathrm{G} 2}$ and $\mathrm{j}_{\mathrm{L} 2}$ are qualitatively the same in the experimental ranges.

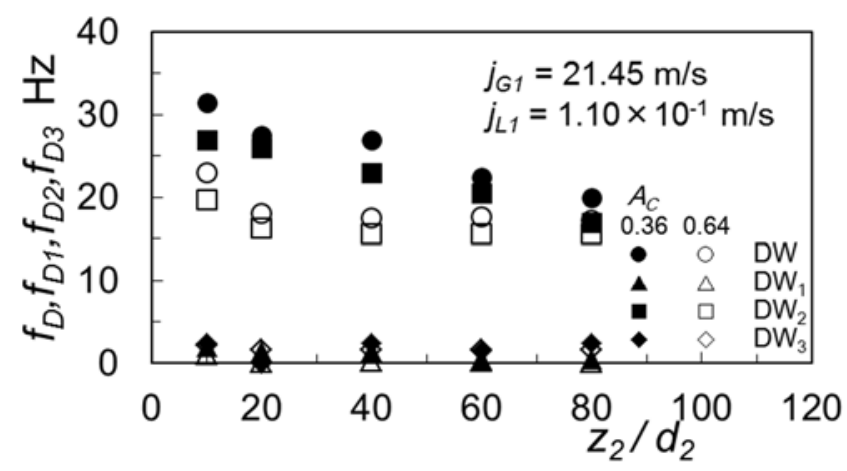

Figure 8: Mean frequencies for disturbance waves in the normalized axial direction.

\section{CONCLUSIONS}

The effects of the contraction area ratio on film behaviour of two-phase flow in a horizontal pipe were investigated. The following main results were obtained in the experimental conditions.

(1) Four flow regimes were observed; huge-wave, two-dimensional disturbance wave, three-dimensional disturbance wave and quasi-bow wave.

(2) The flow regime transits from $\mathrm{DW}_{1}+\mathrm{DW}_{2}$ to $\mathrm{DW}_{1}+\mathrm{DW}_{2}+\mathrm{DW}_{3}$ as the superficial gas and liquid velocities increase. In the case of $\mathrm{A}_{\mathrm{C}}=0.36, \mathrm{DW}_{2}+\mathrm{DW}_{3}$ is observed and the transition occurs at lower superficial gas and liquid velocities in contrast to the case of $\mathrm{A}_{\mathrm{C}}=0.64$.

(3) The effects of the contraction area ratio become less as $\mathrm{z}_{2} / \mathrm{d}_{2}$ increases.

(4) $\mathrm{DW}_{2}$ occurs mainly in the both cases of $\mathrm{A}_{\mathrm{C}}=0.36$ and 0.64 . The wave occurrence frequencies in the pipe with the sudden contraction ratio $A_{C}=0.36$ were mostly higher than those in the pipe with $\mathrm{A}_{\mathrm{C}}=0.64$.

\section{REFERENCES}

[1] Hewitt, G.F., Measurement of Two Phase Flow Parameters, Academic Press, pp. 73, 96, 97, 1978.

[2] Helbig, S. \& Zarrouk, S.J., Measuring two-phase flow in geothermal pipelines using sharp edge orifice plates. Geothermics, 44, pp. 52-64, 2012.

[3] Araoye, A.A., Badr, H.M. \& Ahemd, W.H., Investigation of flow through multi-stage restricting orifices. Annals of Nuclear Energy, 104, pp. 75-90, 2017. 
[4] Roul, M.K. \& Dash, S.K., Single-phase and two-phase flow through thin and thick orifices in horizontal pipes. Journal of Fluid Engineering, 134(9), pp. 091301-091314, 2012.

[5] Yagi, Y., Murase, M., Sato, K. \& Hattori, S., Mechanism of cavitation erosion at the exit of a long orifice. Proceedings of ASME/JSME Joint Fluids Engineering, FEDSM2003-45004, pp. 1359-1364, 2003.

[6] Chang, S.W., Chiang, K.F. \& Lin, C.Y., Channel aspect ratio effect on thermal performance of air-water slug flow through U-bend channels. International Journal of Thermal Sciences,76, pp. 11-29, 2014.

[7] Saidj, F., Kibboua, R., Azzi, A., Ababou, N. \& Azzopardi, B.J., Experimental investigation of air-water two-phase flow through vertical $90^{\circ}$ bend. Experimental Thermal and Fluid Science, 57, pp. 226-234, 2014.

[8] Hsu, L.C., Chen, I.Y., Chyu, C.M. \& Wang, C.C., Two-phase pressure drops and flow pattern observations in $90^{\circ}$ bends subject to upward, downward and horizontal arrangements. Experiments Thermal and Fluid Science, 68, pp. 484-492, 2015.

[9] Whalley, P.B., Air-water two-phase flow in a helically coiled tube. International Journal of Multiphase Flow, 6(4), pp. 345-356, 1980.

[10] Azzopardi, B.J. \& Whalley, P.B., The effect of flow patterns on two-phase flow in a T junction. International Journal of Multiphase Flow, 8(5), pp. 491-507, 1982.

[11] Saisorn, S. \& Wongwises, S., An experimental investigation of two-phase air-water flow through a horizontal circular micro-channel. Experimental Thermal and Fluid Science, 33, pp. 306-315, 2009.

[12] Schmidt, J. \& Friedel, L., Two-phase pressure drop across sudden contractions in duct area. International Journal of Multiphase Flow, 23(2), pp. 283-229, 1997.

[13] Chen, I.Y., Tseng, C.Y., Lin, Y.T. \& Wang, C.C., Two-phase flow pressure change subject to sudden contraction in small rectangular channels. International Journal of Multiphase Flow, 35, pp. 297-306, 2009.

[14] Fujimatsu, T., Kito, M. \& Kondo, K., Film behavior of two-phase flow in a horizontal pipe with a sudden contraction. Proceedings of the 5th International Conference on Jets, Wakes and Separated Flows (ICJWSF2015), Springer Proceedings in Physics, 185, pp. 493-500, 2016.

[15] Fujimatsu, T., Kito, M. \& Kondo, K., Gas-liquid two phase flow in a horizontal pipe with a sudden contraction. Abstract Book: International Conference on Advanced Technology of Experimental Mechanics (ATEM), p. 267, 2015.

[16] Govier, G.W. \& Aziz, K., The Flow of Complex Mixtures in Pipes, Van Nostrand Reinhold Company: New York and London, pp. 503-589, 1972.

[17] Butterworth, D. \& Hewitt, G.F. eds, Two-phase Flow and Heat Transfer, Oxford University Press, p. 20, 1977.

[18] Azzopardi, B.J. \& Gibbons, D.S., Annular two phase flow in a large diameter tube. The Chemical Engineer, 398, pp. 19-31, 1983.

[19] Mandhane, J.M., Gregory, G.A. \& Aziz, K., A flow pattern map for gas-liquid flow in horizontal pipes. International Journal of Multiphase Flow, 1(4), pp. 537-553, 1974.

[20] Taitel, Y., Lee, N. \& Dukler, A.E., Transient gas-liquid flow in horizontal pipes; modelling the flow pattern transition. AIChE J., 24(5), pp. 921-934, 1978. 